\title{
Índices de qualidade da água da Ilha de Mosqueiro-PA
}

\author{
Water quality indices of Mosqueiro Island-PA
}

\author{
Data de entrada: \\ 24/02/2015 \\ - Data de aprovação: \\ 02/07/2015
}

DOI 10.4322/dae.2015.005

Marcus Vinicíus Tavares de Miranda | Maria de Lourdes Souza Santos / José Almir Rodrigues Pereira | Karina Ferreira Castro Mesquita

\section{RESUMO}

O aumento da população, aliado ao processo de urbanização desordenado, é responsável por grande parte da poluição dos corpos hídricos. As praias da llha de Mosqueiro (Belém-PA) são uma das principais alternativas de lazer da população local e, por isso, merecem atenção especial. O presente trabalho avaliou a qualidade da água por meio da utilização dos índices da qualidade da água e do estado trófico. Foram obtidos dados de parâmetros abióticos, clorofila $a$, coliformes totais e termotolerantes. Os parâmetros mostraram a influência da sazonalidade e da maré na qualidade da água, principalmente no período menos chuvoso, o que foi reforçado pela análise de componentes principais. Os resultados do índice da qualidade da água foram próximos entre os períodos estudados. 0 índice de estado trófico demonstrou que o ambiente não se encontra eutrofizado. Essas informações servem para sinalizar os gestores sobre a atual situação das águas na área estudada.

Palavras-chave: Clorofila a. Componentes principais. Estado trófico. Fósforo.

\section{ABSTRACT}

The increase in population, coupled with disorderly urbanization processes, is responsible for much of the pollution of water bodies. The beaches of Mosqueiro Island (Belem, PA) provide one of the main leisure options of the local population and therefore they deserve special attention. This study evaluates water quality through the use of a water quality index and trophic state. The data obtained included abiotic parameters, chlorophyll a, and total/ fecal coliforms. The data showed the influence of seasonality and tide on water quality, especially during less rainy periods, which was reinforced by the analysis of principal components. The results of the water quality index were close among the two previous period studies. The trophic state index showed that the environment is not eutrophic. This information provides local managers a current analysis of water conditions in the study area.

Keywords: Chlorophyll a. Principal components. Trophic state. Phosphorus.

Marcus Vinicíus Tavares de Miranda

Mestre em Engenharia Civil pela Universidade Federal do Pará. Graduado em Engenharia Sanitária pela Universidade Federal do Pará. E-mail: marcustmirandaahotmail.com

\section{Maria de Lourdes Souza Santos}

Doutora em Oceanografia pela Universidade Federal de Pernambuco. Graduada em Química Industrial pela Universidade Federal do Pará. Professora Associada do Instituto Sócio Ambiental e Recursos Hídricos da Universidade Federal Rural da Amazônia.

E-mail: mdelssantosayahoo.com.br

José Almir Rodrigues Pereira

Doutor em Engenharia Hidráulica e Saneamento pela Universidade de São Paulo. Graduado em Engenharia Sanitária pela Universidade Federal do Pará. Professor Associado do Instituto Tecnológico da Universidade Federal do Pará. E-mail: rpereiraaufpa.br

\section{Karina Ferreira Castro Mesquita}

Doutoranda do curso de Pós-Graduação em Desenvolvimento Sustentável do Trópico Úmido (PPGDSTU). Mestre em Engenharia Civil pela Universidade Federal do Pará. E-mail: kfcmesquitaagmail.com 


\section{INTRODUÇÃO}

O aumento da população, aliado ao processo de urbanização desordenado e ao turismo, é responsável por vários impactos ambientais, com destaque para a deterioração dos corpos hídricos localizados nas áreas de praia.

Na região Norte do Brasil, as 24 praias da llha de Mosqueiro (Belém-PA) são uma das principais alternativas de lazer da população da Região Metropolitana de Belém e, por isso, merecem atenção especial. A ilha, localizada em frente à Baía do Guajará, é uma das 25 ilhas identificadas nominalmente que circundam o município de Belém e possui um sistema de esgotamento sanitário do tipo separador absoluto. Guimarães e Rocha (2007) descreveram que a aeração mecânica das Estações de Tratamento de Esgoto (ETEs) da Vila e Aeroporto, localizadas em Mosqueiro, não estava em funcionamento após recorrentes tentativas de furto dos cabos elétricos, motores e tirantes de aço usados para atracação dos aeradores flutuantes.

$\mathrm{O}$ aporte de efluentes sem tratamento tem como consequência a deterioração dos corpos hídricos, principalmente em áreas urbanas. As diferentes formas de aporte tornam, na prática, inexequível uma análise sistemática de todos os poluentes que podem estar presentes nas águas superficiais. Portanto, são selecionados parâmetros físicos, químicos e microbiológicos mais representativos, em geral, expressos por valores adequados a índices de qualidade, que são monitorados sistematicamente em estações de amostragem (ZIMMERMANN et al., 2008).

No Brasil, a Resolução CONAMA n 357/2005 estabelece valores limites de concentração aos quais cada substância presente na água deve obedecer. Contudo, com a vasta gama de variáveis, a interpretação dos dados torna-se complexa e exaustiva; dessa forma, a utilização de índices, como os Índices de Qualidade da Água (IQQA) e do Estado Trófico (IET), facilita compreender as condições ambientais dos corpos hídricos. De acordo com Alves et al. (2012), o IQA é um índice que dá relevância à poluição por esgoto doméstico, principal fonte nas bacias hidrográficas, enquanto o IET é relacionado ao enriquecimento por nutrientes e ao efeito do crescimento excessivo de algas. Ademais, atualmente, também é utilizada uma abordagem multivariada, como a análise de componentes principais para extrair informações relevantes das variáveis obtidas e, com isso, mostrar o cenário da qualidade da água dos corpos hídricos.

Nesse contexto, o presente trabalho apresenta como principal objetivo avaliar o impacto ambiental causado pelas atividades urbanas sobre a qualidade das águas em um trecho no sudoeste da Ilha de Mosqueiro-PA, por meio da utilização do IQA, IET e análise de componentes principais para interpretação dos resultados físico-químicos, de clorofila a e microbiológicos.

\section{MATERIAL E MÉTODOS}

\section{Área de estudo}

$\mathrm{O}$ distrito administrativo do Mosqueiro pertence ao município de Belém-PA, região Norte do Brasil (Figura 1). O clima característico é quente e úmido, do tipo Af de Koepen, com temperatura anual média de $25,9^{\circ} \mathrm{C}$, mínima de $21,9^{\circ} \mathrm{C}$ e máxima de $31,4^{\circ} \mathrm{C}$. O entorno da llha de Mosqueiro é caracterizado por pontões e enseadas, em que ocorre intensa ação erosiva do estuário, com a formação de falésias ativas e acumulação de formas gradativas de relevo. É possível destacar, ainda, registros de paleomangues parcialmente degradados e soterrados pelos depósitos arenosos por ocasião da maré vazante (SALES, 2005).

\section{Amostragem e análises em laboratório}

$\mathrm{Na}$ definição dos pontos de coleta de água, foi considerada a redução da mata ciliar às margens do corpo d'água, em função da progressiva urbanização, bem como a existência, na foz do rio 
Murubira, de uma praia utilizada pela comunidade local. Com isso, procurou-se caracterizar a atual situação, observando as alterações ocasionadas na qualidade do corpo d'água, com especial atenção para a área utilizada pelos banhistas, uma vez que a falta de estruturação do sistema de esgoto faz com que o rio Murubira receba grande contribuição de esgoto sanitário ao longo do seu trajeto.

A coleta foi realizada em duas campanhas, uma no período menos chuvoso (14 de setembro de 2010) e outra no chuvoso (19 de abril de 2011), durante a baixa-mar e a preamar, em 12 pontos de amostragem (Figura 1). Os pontos 1 a 9 de amostragem foram locados em transects, o ponto 10 foi locado no rio Murubira e os pontos 11 e 12 foram locados a jusante dos emissários das ETEs da Vila e Aeroporto, respectivamente. A coleta foi realizada aproximadamente a $20 \mathrm{~cm}$ de profundidade, com garrafa de Van Dorn. No momento da coleta, foram obtidos dados de temperatura (termômetro digital modelo
TE-300) e pH (pHmetro da marca pHTECK). Para as demais análises, as amostras foram transportadas para o Laboratório de Química Ambiental (LQA) da Universidade Federal Rural da Amazônia (UFRA). No laboratório, foram obtidos os valores de turbidez (turbidímetro da marca Hach 2100P) e condutividade elétrica (condutivímetro da ONDA/TCP01) e, para a determinação do teor do oxigênio dissolvido, foi utilizado o método de Winkler, descrito em Strickland e Parsons (1972).

A demanda bioquímica de oxigênio, sólidos totais, cor, fósforo total, nitrogênio total, nitrato, nitrito, nitrogênio-amoniacal e silicato foram quantificados de acordo com os métodos descritos em Apha (2005) e a determinação de clorofila $a$ foi feita segundo Teixeira (1973). Para quantificação de coliformes totais e termotolerantes, foi empregado o Colilert, que utiliza tecnologia de substrato definido e é aceito pelos métodos padrões para exames de água e esgoto, segundo Apha (2005).

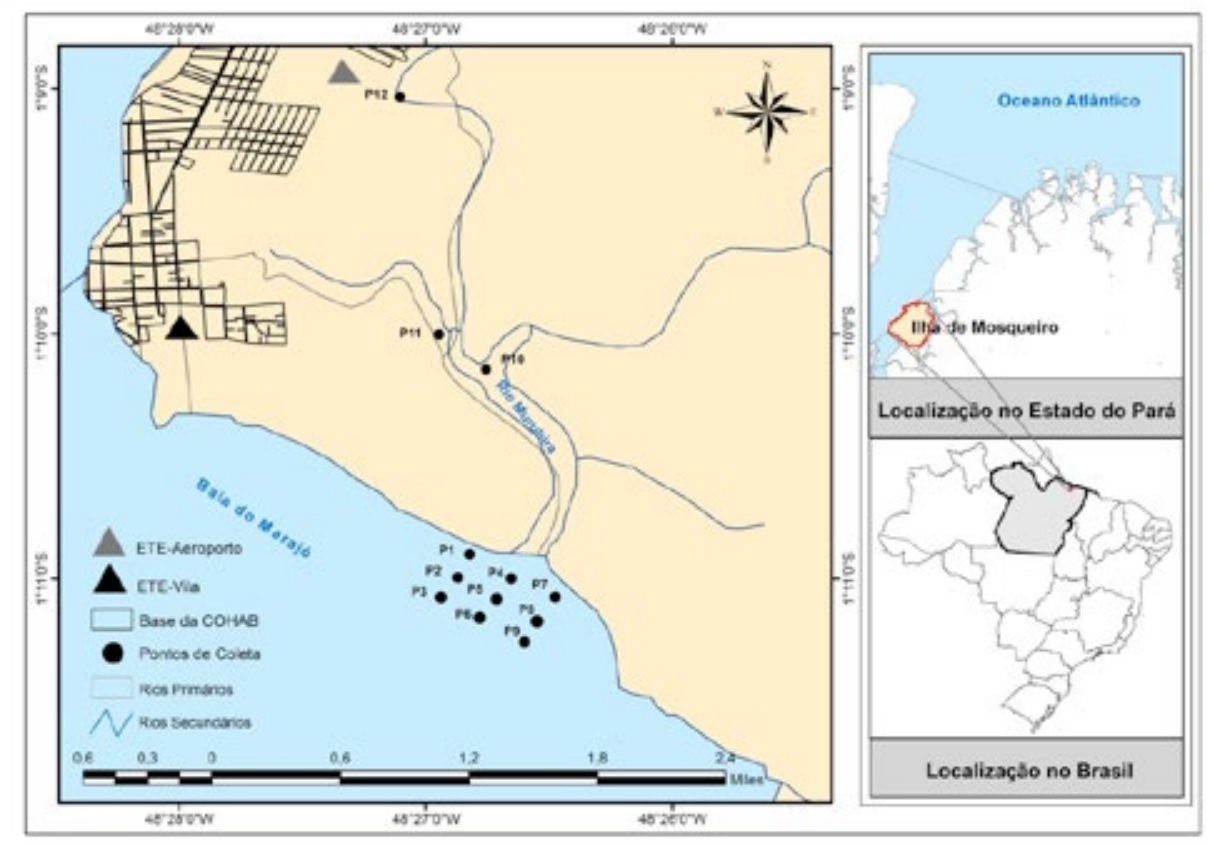

Figura 1 - Localização da llha de Mosqueiro (Belém-PA) e dos pontos de coleta de água. 
IQA

As variáveis utilizadas para calcular foram: temperatura, $\mathrm{pH}$, oxigênio dissolvido, demanda bioquímica de oxigênio, coliformes fecais, nitrogênio total, fósforo total, sólidos totais e turbidez. Com base nos resultados, foi possível classificar a qualidade da água em ótima ( $80 \leq 1 \mathrm{~A} \leq 100)$, boa (52 $\leq 1 Q A \leq 80)$, regular ( $37 \leq 1 Q A \leq 52)$, ruim $(20 \leq 1 Q A$ $\leq 37)$ e péssima $(0 \leq I Q A \leq 20)$, conforme descrito pela Companhia de Tecnologia de Saneamento Ambiental (CETESB, 2010).

IET

Para o cálculo do IET, foram utilizados os valores do IET para fósforo total [IET (PT) = 10x (6- $((0,42-$ $0,36 x(\ln \mathrm{PT})) / \ln 2))-20]$ e clorofila $a[$ [IET $(\mathrm{CL})=10 \mathrm{x}$ (6-((-0,7-0,6x(ln $C L)) / \ln 2))-20]$ para ambientes lóticos, sendo PT a concentração de fósforo total medida à superfície da água, em $\mu \mathrm{g} \cdot \mathrm{L}^{-1} ; \mathrm{CL}$ a concentração de clorofila medida à superfície da água, em $\mu$ g. $L^{-1}$; In o logaritmo natural (CETESB, 2010).

\section{Análises estatísticas}

Os dados dos parâmetros abióticos, microbiológicos e de clorofila a foram analisados pelos métodos de estatística descritiva e de análise de componentes principais. $\mathrm{Na}$ análise de componentes principais, as variáveis originais são linearmente combinadas, com o objetivo de projetar o máximo de informação no menor número de dimensões. A informação total contida no conjunto de dados de partida é quantificada pela matriz de covariância. A primeira componente principal (PC1) é a direção de máxima variância e, portanto, de máxima informação no espaço multidimensional original. A segunda componente (PC2) é ortogonal à PC1 e corresponde ao eixo que explica o máximo possível da informação que não pôde ser representada pela PC1. Juntas, PC1 e PC2 definem o plano de máxima informação no espaço multidimensional (MASSART et al., 1998).

\section{RESULTADOS E DISCUSSÃO}

\section{Distribuição dos parâmetros abióticos, microbiológicos e clorofila a}

Os resultados de salinidade (Tabela 1) permitiram enquadrar a área de estudo na classe de águas doces da Resolução CONAMA n 357/2005. No período menos chuvoso, a salinidade teve uma variação mais acentuada, inclusive entre as marés, do que no período chuvoso, o que mostra a influência da pluviometria na distribuição desse parâmetro, bem como a influência da descarga fluvial. Trabalhos feitos na região Norte, na Baía do Guajará (PAIVA et al., 2006) e no estuário do rio Guajará-Mirim (SILVA et al., 2011), mostram águas com influência fluvial oriundas de rios e tributários.

Os valores de temperatura das águas não tiveram variações acentuadas entre as marés, tendo sido os maiores valores detectados no período menos chuvoso (Tabela 1). Com relação ao $\mathrm{pH}$, a variação também não foi acentuada (Tabela 1), o que indica a existência do efeito tampão no ambiente. Ao comparar os resultados de $\mathrm{pH}$ com os limites estabelecidos (entre 5,0 e 9,0) pela Resolução CONAMA n $357 / 2005$, para os rios de classe II, de águas doces, observa-se que as águas estudadas enquadram-se dentro desses limites. Deve-se ressaltar que baixos valores de $\mathrm{pH}$ para as águas da região amazônica são descritos na literatura (PAIVA et al., 2006; SILVA et al., 2011; ALVES et al., 2012) e relacionados à geologia local.

A condutividade elétrica teve os menores valores durante o período chuvoso (Tabela 1). De acordo com Bordalo et al. (2007), esse parâmetro é dependente do seu conteúdo iônico, sendo valores elevados característicos de ambiente marinho. Por sua vez, os valores de turbidez, cor e sólidos totais foram próximos entre os períodos, com os maiores valores no período menos chuvoso (Tabela 1). Em ambos os períodos, foi observada uma diferença entre as marés, com os maiores valores detectados na preamar, o que pode ser relacionado ao processo de ressuspensão próximo à 
Tabela 1 - Valores da média e desvio padrão dos parâmetros abióticos, bacteriológicos e de clorofila a, obtidos nas águas superficiais da llha de Mosqueiro, durante o período menos chuvoso e chuvoso da região.

\begin{tabular}{|c|c|c|c|c|}
\hline \multirow{3}{*}{ Parâmetro } & \multicolumn{2}{|c|}{ Menos chuvoso } & \multicolumn{2}{|c|}{ Chuvoso } \\
\hline & Baixa-mar & Preamar & $\begin{array}{c}\text { Baixa- } \\
\text { mar }\end{array}$ & Preamar \\
\hline & $\begin{array}{l}\text { Média } \pm \\
\text { DP1 }\end{array}$ & $\begin{array}{l}\text { Média } \pm \\
\text { DP }\end{array}$ & $\begin{array}{l}\text { Média } \pm \\
\text { DP }\end{array}$ & $\begin{array}{l}\text { Média } \pm \\
\text { DP }\end{array}$ \\
\hline Salinidade & $0,23 \pm 0,08$ & $0,10 \pm 0,01$ & $\begin{array}{l}0,01 \pm \\
0,01\end{array}$ & $0,00 \pm 0,00$ \\
\hline $\begin{array}{l}\text { Temperatura } \\
\left({ }^{\circ} \mathrm{C}\right)\end{array}$ & $\begin{array}{l}27,67 \pm \\
0,49\end{array}$ & $\begin{array}{l}30,79 \pm \\
1,64\end{array}$ & $\begin{array}{l}28,83 \pm \\
1,75\end{array}$ & $\begin{array}{l}29,25 \pm \\
0,97\end{array}$ \\
\hline $\mathrm{pH}$ & $7,19 \pm 0,13$ & $7,19 \pm 0,08$ & $\begin{array}{l}5,40 \pm \\
0,87\end{array}$ & $6,05 \pm 0,59$ \\
\hline $\mathrm{CE} *\left(\mathrm{mS} . \mathrm{cm}^{-1}\right)$ & $\begin{array}{l}238,12 \\
\pm 287,21\end{array}$ & $\begin{array}{l}119,09 \pm \\
16,63\end{array}$ & $\begin{array}{l}0,02 \pm \\
0,01\end{array}$ & $0,02 \pm 0,01$ \\
\hline Turbidez (UNT) & $\begin{array}{l}32,69 \pm \\
10,10\end{array}$ & $\begin{array}{l}35,55 \pm \\
18,69\end{array}$ & $\begin{array}{l}22,93 \pm \\
6,15\end{array}$ & $\begin{array}{l}39,57 \pm \\
10,83\end{array}$ \\
\hline Cor (PtCo) & $\begin{array}{l}264,69 \pm \\
53,16\end{array}$ & $\begin{array}{l}249,50 \pm \\
85,44\end{array}$ & $\begin{array}{l}163,67 \pm \\
29,23\end{array}$ & $\begin{array}{l}193,17 \pm \\
91,83\end{array}$ \\
\hline $\begin{array}{l}\text { Sólidos totais } \\
\left(\mathrm{mg} \cdot \mathrm{L}^{-1}\right)\end{array}$ & $\begin{array}{l}46,58 \pm \\
20,82\end{array}$ & $\begin{array}{l}46,33 \pm \\
11,90\end{array}$ & $\begin{array}{l}13,33 \pm \\
4,86\end{array}$ & $8,58 \pm 3,26$ \\
\hline $\begin{array}{l}\text { Col. totais } \\
\left(\text { NMP. } 100 \mathrm{~mL}^{-1} \text { ) }\right.\end{array}$ & $\begin{array}{l}1617,03 \pm \\
190,10\end{array}$ & $\begin{array}{l}1302,87 \pm \\
785,97\end{array}$ & $\begin{array}{l}922,29 \pm \\
278,44\end{array}$ & $\begin{array}{l}569,38 \pm \\
409,20\end{array}$ \\
\hline $\begin{array}{l}\text { Col. term. }{ }^{* * * *} \\
\left(\text { NMP.100 } \mathrm{mL}^{-1}\right)\end{array}$ & $\begin{array}{l}61,51 \pm \\
24,70\end{array}$ & $\begin{array}{l}28,83 \pm \\
12,65\end{array}$ & $\begin{array}{l}24,57 \pm \\
13,02\end{array}$ & $8,90 \pm 6,55$ \\
\hline $\mathrm{DBO}\left(\mathrm{mg} \cdot \mathrm{L}^{-1}\right)$ & $5,16 \pm 2,32$ & $6,86 \pm 1,35$ & $\begin{array}{l}7,04 \pm \\
1,62\end{array}$ & $6,98 \pm 1,36$ \\
\hline $\mathrm{OD}\left(\mathrm{mg} \cdot \mathrm{L}^{-1}\right)$ & $6,89 \pm 0,50$ & $5,90 \pm 1,82$ & $\begin{array}{l}5,43 \pm \\
0,61\end{array}$ & $5,66 \pm 0,82$ \\
\hline Nitrato (mg. $\left.\mathrm{L}^{-1}\right)$ & $0,04 \pm 0,01$ & $0,80 \pm 0,30$ & $\begin{array}{l}0,07 \\
\pm 0,01\end{array}$ & $0,07 \pm 0,01$ \\
\hline Nitrito (mg. $\mathrm{L}^{-1}$ ) & $\begin{array}{l}0,01 \pm \\
0,004\end{array}$ & $0,01 \pm 0,0$ & $\begin{array}{l}0,01 \pm \\
0,01\end{array}$ & $0,01 \pm 0,01$ \\
\hline $\begin{array}{l}\mathrm{N} \text {-amoniacal } \\
\left(\mathrm{mg} \cdot \mathrm{L}^{-1}\right)\end{array}$ & $0,39 \pm 0,08$ & $0,28 \pm 0,03$ & $\begin{array}{l}0,36 \pm \\
0,06\end{array}$ & $0,37 \pm 0,10$ \\
\hline $\begin{array}{l}\text { Nitrogênio total } \\
\left(\mathrm{mg} \cdot \mathrm{L}^{-1}\right)\end{array}$ & $1,07 \pm 0,44$ & $1,50 \pm 0,43$ & $\begin{array}{l}1,83 \pm \\
0,40\end{array}$ & $1,80 \pm 0,44$ \\
\hline $\begin{array}{l}\text { Fósforo total } \\
\left(\mathrm{mg} \cdot \mathrm{L}^{-1}\right)\end{array}$ & $0,06 \pm 0,02$ & $0,06 \pm 0,04$ & $\begin{array}{l}0,05 \pm \\
0,02\end{array}$ & $0,07 \pm 0,01$ \\
\hline Silicato (mg. $\mathrm{L}^{-1}$ ) & $4,18 \pm 1,14$ & $2,50 \pm 0,76$ & $\begin{array}{l}1,91 \pm \\
0,52\end{array}$ & $2,00 \pm 0,84$ \\
\hline $\begin{array}{l}\text { Clorofila } a \\
\left(\mathrm{mg} \cdot \mathrm{m}^{-3}\right)\end{array}$ & $5,59 \pm 2,74$ & $4,10 \pm 2,88$ & $\begin{array}{l}46,41 \pm \\
12,76\end{array}$ & $\begin{array}{l}50,37 \pm \\
12,64\end{array}$ \\
\hline
\end{tabular}

Notas: ${ }^{1} \mathrm{DP}=$ desvio padrão, ${ }^{*} \mathrm{CE}=$ condutividade elétrica, ${ }^{*}$ Col. totais $=$ coliformes totais, ${ }^{*}$ Col. term. $=$ coliformes termotolerantes.

costa propiciado pela ação do vento. Ainda, em ambos os períodos, não foram verificados valores de turbidez fora do limite estabelecido pela Resolução CONAMA n 357/2005, ou seja, 100 UNT para água doce, classe II.

Os coliformes totais e termotolerantes foram registrados em ambos os períodos, com os menores valores na preamar (Tabela 1), o que demonstra a presença de lançamento de esgoto e a capacida- de de diluição do corpo hídrico receptor. Alves et al. (2012) também descreveram a presença desses grupos nas águas do rio Arari (Ilha do Marajó, Norte do Brasil) e relacionaram com os efluentes urbanos e também com as embarcações de transporte de passageiros e gado.

Os valores de demanda bioquímica de oxigênio e de oxigênio dissolvido foram próximos entre os períodos de coleta (Tabela 1). Os valores de demanda bioquímica de oxigênio acima do valor ( 5 mg. $\left.\mathrm{L}^{-1}\right)$ estabelecido pela Resolução CONAMA $\mathrm{n}^{\circ}$ 357/2005 reforçam a existência de lançamento de esgoto na área, além do processo de ressuspensão, o que inclui a matéria orgânica ou a liberação de águas servidas por embarcações. Em relação às concentrações de oxigênio dissolvido, pode-se observar que os valores mínimos verificados ficaram abaixo do estabelecido $\left(5 \mathrm{mg} \cdot \mathrm{L}^{-1}\right)$ pela mesma resolução. Sua distribuição foi inversa à verificada para demanda bioquímica de oxigênio, o que denota o consumo desse gás pela degradação da matéria orgânica; os maiores valores foram detectados durante a baixa-mar.

Valores de demanda bioquímica de oxigênio acima do descrito na resolução ou baixos valores de oxigênio dissolvido nos ecossistemas aquáticos da região Norte são descritos na literatura. Machado e Braz (2004) descreveram valores de demanda bioquímica de oxigênio acima de $10 \mathrm{mg} \cdot \mathrm{L}^{-1}$ para as praias da llha de Mosqueiro e relacionaram com fontes de poluição pontuais. Alves et al. (2012) também verificaram valores de demanda bioquímica de oxigênio elevados e uma relação inversa entre a demanda bioquímica de oxigênio e o oxigênio dissolvido nas águas do rio Arari (llha do Marajó). Silva et al. (2011) encontraram baixos valores de oxigênio dissolvido no estuário do rio GuajaráMirim (Vigia-PA), em áreas de influência dos rios e tributários que deságuam nesse ambiente.

O nitrogênio e o fósforo são considerados nutrientes importantes nos ecossistemas aquáticos. Os 
maiores valores de nitrogênio total foram detectados no período chuvoso. Para as demais formas nitrogenadas estudadas, existem valores estabelecidos pela Resolução CONAMA n० 357/2005 (nitrito $=0,07 \mathrm{mg} \cdot \mathrm{L}^{-1} \mathrm{~N}$, nitrato $=0,40 \mathrm{mg} \cdot \mathrm{L}^{-1} \mathrm{~N} \mathrm{e}$ nitrogênio-amoniacal $=0,40 \mathrm{mg} \cdot \mathrm{L}^{-1} \mathrm{~N}$ ). Entre as formas inorgânicas que compõem o nitrogênio total, foram observadas concentrações de nitrito abaixo do valor estabelecido por essa resolução. No entanto, os resultados de nitrato e de nitrogênio-amoniacal ficaram acima (Tabela 1).

A presença de nitrato caracteriza uma poluição remota, em função de que o nitrogênio se encontra em seu último estado de oxidação, enquanto o nitrogênio amoniacal é um indicador de poluição orgânica por despejos domésticos. A presença de amônio na água caracteriza a poluição recente por esgotos domésticos (VASCO et al., 2011). Os maiores valores de nitrato ocorreram no período menos chuvoso, enquanto os de nitrogênio-amoniacal, durante o chuvoso, o que mostra a forte influência da sazonalidade da região na distribuição dessas formas nitrogenadas.

Os resultados mostraram valores de fósforo total (Tabela 1) abaixo do limite da Resolução CONAMA n 357/2005 (0,062 mg.L-1 P). O fósforo é limitante da produtividade primária dos ecossistemas aquáticos, sendo apontado como principal responsável pela eutrofização artificial desses sistemas. Outro nutriente essencial para o desenvolvimento do fitoplâncton é o silicato, essencial para organismos, como, por exemplo, as diatomáceas. Os maiores valores foram encontrados no período menos chuvoso, durante a baixa-mar (Tabela 1), o que indica a descarga dos rios como principal fonte desse nutriente.

Contudo, os maiores valores de clorofila a foram detectados durante o período chuvoso (Tabela 1). Alves et al. (2012) também encontraram valores elevados de clorofila a durante o período chuvoso (de 4,22 $\mathrm{mg} \cdot \mathrm{m}^{-3}$ a $38,81 \mathrm{mg} \cdot \mathrm{m}^{-3}$ ) e descreveram a área como de alta fertilidade.

IQA

O IQA da área em estudo pode ser classificado como bom, uma vez que $79 \%$ dos resultados no período menos chuvoso indicaram uma qualidade boa; $17 \%$, aceitável; e $4 \%$, ótima. Para o período chuvoso, os resultados mostraram $67 \%$ com qualidade boa, $29 \%$ aceitável e $4 \%$ ótima. Essa classificação para a qualidade da água ocorreu principalmente devido aos baixos valores de coliformes termotolerantes em ambos os períodos.

IET

O IET indicou um ambiente oligotrófico com $63 \%$ dos resultados, $29 \%$ ultraoligotrófico e $8 \%$ mesotrófico durante o período menos chuvoso. Já no período chuvoso, foi classificado como eutrófico com $54 \%$ dos resultados e mesotrófico com $46 \%$. Essa classificação reflete a influência da sazonalidade e da maré na área de estudo.

\section{Análise de componentes principais}

$O$ resultado mostra que as duas primeiras componentes (PC1 e PC2) juntas descreveram cerca de $52 \%$ da variância original (Figura 2a). A PC1 explicou $37 \%$ da variância total e pode ser interpretada como uma correlação negativa entre os dois grupos de variáveis, de um lado, salinidade $(0,87), \mathrm{pH}$ $(0,82)$, condutividade elétrica $(0,60)$, coliformes totais $(0,57)$, coliformes termotolerantes $(0,76)$, oxigênio dissolvido $(0,78)$, nitrito $(0,57)$, silicato $(0,72)$ e sólidos totais $(0,79)$ e, de outro, demanda bioquímica de oxigênio $(0,37)$, nitrogênio total $(-0,61)$ e clorofila $a(-0,88)$, que são as principais fontes de variação no conjunto de amostras.

A síntese bioquímica da matéria orgânica pode explicar o comportamento inverso entre as variáveis demanda bioquímica de oxigênio e oxigênio dissolvido. A relação positiva entre a clorofila $a$ e o nitrogênio total reforça a necessidade das formas nitrogenadas para os organismos fotossintetizantes. 
a)

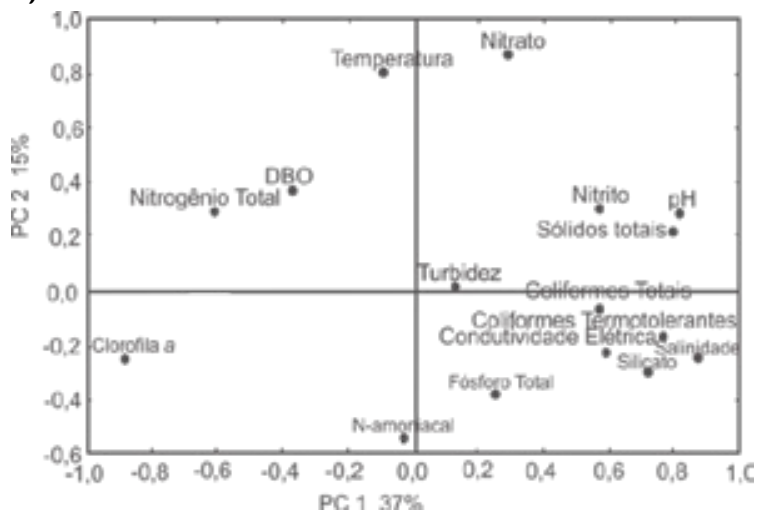

b)

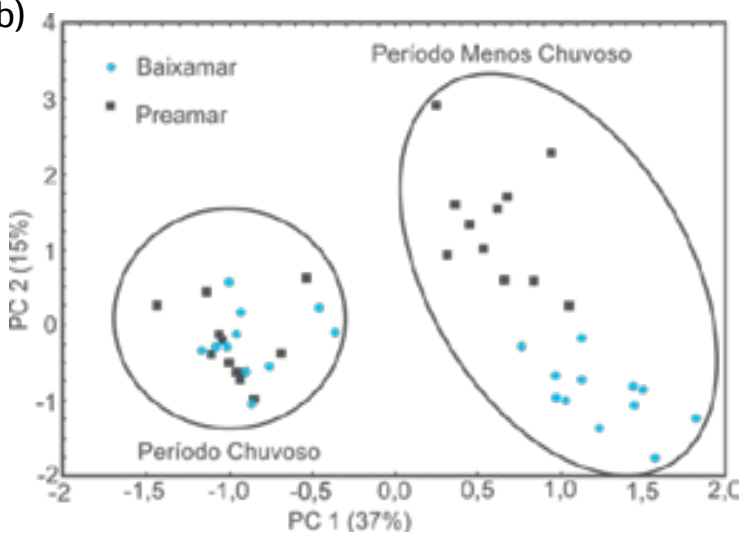

Figura 2 - (a) Peso das variáveis nas duas primeiras componentes principais; (b) escores dos dados em relação aos períodos menos chuvoso e chuvoso e baixa-mar e preamar.

Foi observada uma relação positiva entre os sólidos totais e a condutividade elétrica. De acordo com Sampaio et al. (2007), os sólidos são compostos por substâncias dissolvidas e em suspensão, de composição orgânica e/ou inorgânica, enquanto a condutividade elétrica está relacionada basicamente com os sais e indica, portanto, a quantidade de íons mono e multivalentes contidos no líquido, o que explica, também, a relação positiva com a salinidade.

A relação positiva entre os coliformes totais e termotolerantes mostra a ocorrência de uma descarga recente de matéria fecal para o ambiente. Por sua vez, a relação inversa entre a clorofila $a$ e o silicato mostra que esse nutriente é necessário para o desenvolvimento dos organismos fotossintetizantes (como, por exemplo, as diatomáceas) no ambiente.

A PC2 explicou $15 \%$ da variância total, apresentando um contraste entre temperatura $(0,80)$, nitrato $(0,87)$ e nitrogênio-amoniacal $(-0,54)$. A correlação inversa entre o nitrato e o nitrogênio-amoniacal está relacionada com o processo de oxidação.

$\mathrm{Na}$ Figura $2 \mathrm{~b}$, estão plotados os escores dos dados superficiais dos períodos estudados, com intensa divisão entre eles. Em relação ao regime de marés, o período menos chuvoso teve separação total nos valores da baixa-mar e preamar. No período chuvoso, não foi observada essa separação e, sim, uma uniformidade da massa líquida na área estudada, consequência da menor variação dos valores de salinidade.

\section{CONCLUSÃO}

Os resultados de IQA e IET demonstraram que as águas do sudoeste da llha de Mosqueiro ainda conseguem manter um padrão de qualidade, o que pode ser relacionado à dinâmica da maré existente no local.

A análise de componentes principais permitiu extrair informações importantes, como a separação dos dados em função do período sazonal e a influência da maré no período menos chuvoso. Também foram destacadas as variáveis que prejudicam a qualidade da água e são oriundas de fontes difusas de poluição. Essas informações servem para sinalizar os gestores municipais, estaduais e federais sobre a atual situação das águas na área estudada e também como subsídio para o planejamento de um desenvolvimento sustentado na região.

\section{REFERÊNCIAS}

ALVES, I.C.C.; EL-ROBRINI, M.; SANTOS, M.L.S.; MONTEIRO, S.M.; BARBOSA, L.P.F.; GUIMARÃES, J.T.F. Qualidade das águas superfici- 
ais e avaliação do estado trófico do rio Arari (llha de Marajó, norte do Brasil). ActaAmazonica,v.42,n.1, p.115- 124. 2012.

APHA; AWWA; WPCF. Standard methods for the examination of water and wastewater. 21st ed. Washington D.C.: American Public Health Association, 2005.

BORDALO, A.O.; MOURA, C.A.V.; SCHELLER, T. Determinação da composição isotópica de estrôncio em águas naturais: exemplos de sua aplicação em águas subsuperficiais da zona costeira na região Bragantina - PA. Química Nova, São Paulo, v.30, n.4, p. 821 $-827.2007$

CETESB. 2010.Índice de Quualidade da Água - IQQA.Disponível em: <http://www.cetesb.sp.gov.br/Agua/rios/indice_iap_iqa.asp> Acesso em: 26 jan. 2010.

CONAMA - Conselho Nacional do Meio Ambiente. 2005. Resolução n 357 , de 17 de março de 2005. Ministério do Meio Ambiente. Dispõe sobre a classificação dos corpos de água e diretrizes ambientais para o seu enquadramento, bem como estabelece as condições e padrões de lançamento de efluentes, e dá outras providências. PublicaçãoDOU: 18/03/2005.

GUIMARÃES, L.M.M.; ROCHA, S.T.C. 2007. Avaliação Pós-Implantação do Sistema de Esgotamento Sanitário (Ses) da llha do Mosqueiro.In:XXIV CONGRESSO BRASILEIRO DE ENGENHARIA SANITÁRIA E AMBIENTAL, Belo Horizonte, Minas Gerais.

MACHADO, B.C. e BRAZ, V.M.N 2004 Avaliação dos indicadores de balneabilidade em praias estuarinas. Revista Científica da UFPA, http: //WWW.ufpa.br/revistaic. vol. 4.

MASSART, D. L.; VANDEGINSTE, B.M.G.; BUYDENS, L.M.C.; DEJONG, S.; LEWI, P.; SMEYERS-VERBEKE, J.Handbook of chemometrics and qualimetrics. Amsterdam: Elsevier, 1998.

PAIVA, R.S.; ESKINAZI-LEÇA, E.; PASSAVANTE, J.Z.O.; SILVA-CUNHA, M.G.; MELO, N.F.A. Considerações ecológicas sobre o fitoplâncton da baía do Guajará e foz do rio Guamá (Pará, Brasil). Boletim do Museu Paraense Emílio Goeldi, Ciências Naturais, v 2,n.2, p.133 $-146.2006$.

SALES, G. M. 2005.Ecologia da paisagem da llha do Mosqueiro,NE do Estado do Pará.120 p. (Dissertação de Mestrado Pós-Graduação em Geologia e Geoquimica), Universidade Federal do Pará.

SAMPAIO, C S, SILVESTRO, M G, FRIGO, E P, BORGES, C M. Relação entre série de sólidos e condutividade elétrica em diferentes águas residuárias. Irriga, Botucatu, v.12,n.4, p.557-562. 2007.

SILVA, A.C.; MANGAS, A.P.; PALHETA, G.D.; MELO, N.F.A.C. Variação intermareal na composição do ictioplâncton no estuário do rio Guajará-Mirim (Vigia de Nazaré - Pará) em período de alta pluviosidade. Boletim Técnico Cinetifico do CEPNOR, Pará, v. 11, n.1, p. $21-32.2011$.

STRICKLAND, J. D. H.; PARSONS, T. R.A practical handbook of sea water analysis. BulletimFisheriesresearchboardof Canada, Ottawa, n. 167, p. 1- 311, 1972.

TEIXEIRA, C. Introdução aos métodos para medir a produção primária do fitoplâncton marinho. Boletim do Instituto Oceanográfico de São Paulo, São Paulo, v.22, p.59-92. 1973.

VASCO, A.N.; BRITTO, F.B.; PEREIRA, A.P.S.; MÉLLO JÚNIIOR, A.V.; GARCIA, C.A.B.; NOGUEIRA, L.C. Avaliação espacial e temporal da qualidade da água na sub-bacia do rio Poxim, Sergipe, Brasil. Ambi-Agua, Taubaté, n.6, v.1, p.118-130. 2011.

ZIMMEMANN, C.M.; GUIMARÃES, O.M.; PERALTA-ZAMORA, P.G. Avaliação da qualidade do corpo hídrico do rio Tibagi na Região de Ponta Grossa utilizando análise de componentes principais (PCA). Química Nova, v. 31, n. 7, p. 1727 -1732, 2008. 